$\mathbb{T}$ Periodica Polytechnica Chemical Engineering

59(3), pp. 174-185, 2015

DOI: $10.3311 /$ PPch.7714

Creative Commons Attribution (i)

RESEARCH ARTICLE

\section{A New Simple Equation of State for Calculating Solubility of Solids in Supercritical Carbon Dioxide}

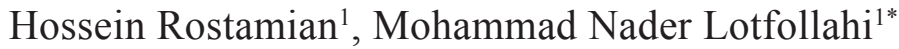

Received 16 September 2014; accepted after revision 10 December 2014

\begin{abstract}
In this work, a modified Redlich-Kwong ( $\beta R K$ ) equation of state has been proposed to calculate the solubilities of twenty solids including Ascorbic acid, Fluoranthene, Propyl gallate, Acenaphthene, Asprin, Climbazole, Cinnamic acid, Triclocarban, 4-methoxyphenylacetic acid, Phenoxyacetic acid, Cholesterol,Cholesteryl butyrate, Cholestrol acetat,Triphenylene, Ibuprofen, Acetanilide, Propanamide, Butanamide, Chrysene and Dodecyl gallate in supercritical carbon dioxide (440 data points). The proposed equation of state has been coupled with the van der Waals zero (vdW0) mixing rule. To distinguish the accuracy of the proposed model, the results of the model have been compared with the results of Peng-Robinson (PR) equation of state in combination with the van der Waals one (vdW1) and the Wong-Sandler (WS) mixing rules. The calculation results showed that the proposed model performed well for reproducing the solubility of these twenty solids in supercritical carbon dioxide with absolute average relative deviation $(A A R D)=5.7 \%$.
\end{abstract}

\section{Keywords}

solid solubility, supercritical fluid, carbon dioxide, $\beta R K-E o S$

${ }^{1}$ Faculty of Chemical, Petroleum and Gas Engineering

Semnan University, Semnan, Iran

*Corresponding author, e-mail: mnlotfollahi@semnan.ac.ir

\section{Introduction}

In recent years, attentions have been focused on supercritical fluid extraction because this method is potentially applicable in many processes such as food processing, mixture separation, caffeine removal from coffee, extraction of lipids, making fine particles by Rapid Expansion of Supercritical Solutions (RESS), etc. In comparison with the conventional extraction methods, supercritical fluid extraction leads to higher speed of extraction, easier separation of solvent and better recovery, and less solvent usage and waste generation. Among supercritical fluids, carbon dioxide is the most commonly used supercritical fluid because of nontoxic, nonflammable nature of carbon dioxide. Furthermore, carbon dioxide is relatively inexpensive and it has reasonable critical properties $(\mathrm{Tc}=304.2 \mathrm{~K}$ and $\mathrm{Pc}=73.8$ bar $)[1-4]$. The most important thermo-physical property in the supercritical extraction process is the solubility of solutes in supercritical fluid. To design optimized operating conditions, this property must be determined and modeled so that developing a reliable model for determining the solubility of solids in supercritical fluids is of importance. In general, the models for solubility calculation are classified into two different groups including theoretical models such as models based on the equations of state and empirical correlations such as density based equations. In the first group, different equations of state (EoS) along with various mixing rules are used. Among various types of EoSs, the cubic EoSs are widely used for calculation of solid solubility in supercritical fluid due to their flexibility and reliability and their proper speed of calculations [5-11]. However, cubic EOSs have a limited predictive capability. In addition, they are not accurate for complex systems such as the systems with associating or very heavy compounds [12]. In order to improve the accuracy of the results, an option is applying more complex equations of state based on the molecular theory of statistical mechanics (such as SAFT equation of state) or using more powerful mixing rules (such as Wong-Sandler mixing rule). In spite of considerable developments of theoretical equations of state (e.g. SAFT EOSs), their application is still limited because of their complexity and time consuming for calculation. Another way to overcome the above mentioned limitation is applying empirical 
models such as density-based models of Chrastil [13], MéndezSantiago-Teja [14], Jafari Nejad et al. [15] for phase equilibrium calculation of the supercritical-solid systems. The parameters of these models are obtained based on the error minimization for proposed equations that are versus density of pure supercritical carbon dioxide, temperature and pressure. Although densitybased models does not have any theoretical bases, but they are applied in different applications because of their simplicity in the correlation of experimental data. The main disadvantages of this approach are its requirement to large amount of solubility data and its unconfident for extrapolation.

Many investigators were modeled the solubility of solids in supercritical carbon dioxide. Cheng et al. [1] used the SchmittReid and Giddings models to correlate the high-pressure solubility of phytosterol in supercritical carbon dioxide. They also used Me'ndez-Santiago and Teja density based models to fit the experimental data. Huang et al. [4] applied a correlation and a semi-empirical model to reproduce the solubility of 15 pharmaceutical compounds in supercritical carbon dioxide at various thermodynamic conditions. Housaindokht et al. [5] applied modified Peng-Robinson equation of state to correlate the solubility of solids in supercritical carbon dioxide. They also determined interaction parameters for these systems. Yazdizadeh et al. [6] applied the Peng-Robinson (PR) and the EsmaeilzadehRoshanfekr (ER) equations of state (EoSs) in combination with the van der Waals one (vdW1) and two (vdW2), Wong-Sandler (WS) and the co-volume dependent (CVD) fluid mixing rules to calculate the solubilities of 52 solids in supercritical carbon dioxide. Wang and Lin [7] presented a predictive model to determine the solubility of drugs in supercritical carbon dioxide. They used melting temperature and heat of fusion to calculate the fugacity of solid phase. They also used Peng-Robinson (PR) EoS to calculate the fugacity in fluid phases. Su [8] modeled the solubilities of solid solutes in carbon dioxide by using the predictive Soave-Redlich-Kwong (PSRK) equation of state. The results of this investigation showed that the PSRK EoS was a simple but a reliable model for solubility evaluation in supercritical fluid technology containing CO2-expanded organic solvents. Asgarpour et al. [8] developed a new equation of state based on Pitzer correlation for the virial equation of state to determine the solubility of drugs in supercritical carbon dioxide. Baseri et al. [10] used the Peng-Robinson EOS to model the solubilities of different solid components in supercritical CO2. They also tested the effects of three different mixing rules containing van der Waals, Panagiotopoulos and Reid, and modified Kwak and Mansoori mixing rules. The modified Kwak and Mansoori mixing rule had the best performance. Aghamiri and Nickmand [16] calculated the solubility of cholesterol in (supercritical fluid+co-solvents) containing carbon dioxide+ethane, carbon dioxide+methanol, ethane+acetone, ethane+hexane and ethane+propane mixed solvents. They used SRK, PR, and SAFT equations of state.
In this work, a modified Redlich-Kwong ( $\beta$ RK) EOS was proposed and combined with the van der Waals zero (vdW0) mixing rule for reproducing the solubilities of 20 solid compounds in supercritical carbon dioxide. In addition, the PengRobinson (PR) equation of state was coupled with the van der Waals one (vdW1) and Wong-Sandler (WS) mixing rules for the same purpose. In order to show the performance of the new proposed EoS in reproducing solubilities of solids in supercritical $\mathrm{CO} 2$, the results obtained by proposed model were compared with the results of the PR-EoS.

\section{Thermodynamic model description \\ 2.1 Phase equilibrium of solid-supercritical fluid}

It is known that the solubility of solid in supercritical phase can be obtained by the equality of the fugacity of solid solute in supercritical and solid phases.

$$
f_{i}^{\text {Solid }}(T, P)=f_{i}^{\text {Supercritical }}\left(T, P,\left\{x_{i}\right\}\right)
$$

In Eq. (1), $f_{i}$ is the fugacity, $T$ is the temperature, $P$ is the pressure and $x_{i}$ is the mole fraction in supercritical phase. When the temperature and the pressure of the system are known, the solubility of solid in supercritical phase is calculated by solving Eq. (1).

\subsection{Fugacity in solid phase}

By neglecting the supercritical fluid solubility in solid phase, assuming the constant solid molar volume and considering the saturation fugacity coefficient of solid to be unity, the fugacity in solid phase can be written as follows:

$$
f_{i}^{\text {solid }}=P_{i}^{\text {Sat }} \exp \left[\frac{v_{i}^{S}\left(P-P_{i}^{\text {Sat }}\right)}{R T}\right]
$$

In Eq. (2), $P_{i}^{\text {Sat }}$ denotes the vapor pressure of solid at temperature $T, v_{i}^{S}$ is the molar volume of solid and $R$ is the universal gas constant.

\subsection{Fugacity of components in the fluid phase}

As it is shown in Eqs. (3) and (4), in order to obtain the fugacity of components in the supercritical phase, an appropriate equation of sate should be considered.

$$
\begin{gathered}
R T \ln \phi_{i}^{\text {supercritical }}=\int_{V}^{\infty}\left(\left(\frac{\partial P}{\partial n_{i}}\right)_{T, V, n_{j \neq i}}-\frac{R T}{V}\right) d V-\ln Z \\
f_{i}^{\text {Supercritical }}=P \phi_{i}^{\text {sup ercritical }} x_{i}
\end{gathered}
$$

In Eqs. (3) and (4), $\phi$ shows the fugacity coefficient of the solute in supercritical phase and $Z$ is the compressibility factor of supercritical phase. 
Table 1 Critical properties of the solid components used in this work.

\begin{tabular}{|c|c|c|c|c|c|}
\hline Compound & $\mathbf{T}_{\mathrm{C}}(\mathrm{K})$ & $P_{C}($ bar $)$ & $\omega$ & $\mathrm{V}_{\mathrm{m}}\left(\mathrm{cm}^{3} / \mathrm{mol}\right)$ & Ref. \\
\hline Dodecyl gallate & 905.9 & 18.46 & 1.2 & 267.9 & [21] \\
\hline Ascorbic acid & 790.91 & 44.19 & 1.57 & 106.7 & [21] \\
\hline Propyl gallate & 862.87 & 47.72 & 0.86 & 155 & [21] \\
\hline Triclocarban & 935.8 & 34.9 & 0.760 & 206.3 & [24] \\
\hline Climbazole & 872 & 23.7 & 0.819 & 223.8 & [24] \\
\hline Cholesterol & 1168.23 & 41.55 & 0.95 & 371.56 & {$[27]$} \\
\hline cholesteryl butyrate & 1234.20 & 34.09 & 0.955 & 433 & [27] \\
\hline cholestrol acetat & 1185.65 & 36.87 & 0.883 & 403.2 & {$[27]$} \\
\hline Ibuprofen & 754.6 & 21.8 & 0.749 & 182.1 & [11] \\
\hline Acetanilide & 735.85 & 40.1 & 0.5774 & 118.93 & {$[28]$} \\
\hline Propanamide & 707.31 & 51.2 & 0.5986 & 69.21 & {$[28]$} \\
\hline Butanamide & 706.28 & 47 & 0.6061 & 84.55 & [28] \\
\hline Aspirin & 762.9 & 32.8 & 0.82 & 128.7 & {$[22]$} \\
\hline Fluoranthene & 905 & 26.1 & 0.59 & 161.6 & {$[6]$} \\
\hline Triphenylene & 1013.6 & 29.28 & 0.49 & 175 & {$[6]$} \\
\hline Chrysene & 1027.8 & 29.28 & 0.49 & 179 & {$[6]$} \\
\hline Acenaphthene & 803.15 & 31 & 0.38 & 126.2 & {$[6]$} \\
\hline Cinnamic acid & 803.94 & 38.58 & 0.688 & 118.8 & [20] \\
\hline phenoxyacetic acid & 802.61 & 39.91 & 0.760 & 113 & {$[20]$} \\
\hline 4-methoxyphenylacetic acid & 827.3 & 34.85 & 0.808 & 127.9 & {$[20]$} \\
\hline
\end{tabular}

The RK-EoS [17] is expressed as follows:

$$
P=\frac{R T}{v-b}-\frac{a}{T_{r}^{0.5} v(v+b)}
$$

The energy and volume parameters of RK EOS are calculated in terms of the critical properties. The critical properties for pure components are given in Table 1 .

$$
\begin{gathered}
a=0.42747 \frac{\left(R T_{c}\right)^{2}}{P_{c}} \\
b=0.0778 \frac{R T_{c}}{P_{c}}
\end{gathered}
$$

For calculating the molar volume of supercritical $\mathrm{CO}_{2}$, Heidaryan and Jarrahian [18] proposed a correction for energy parameter of RK equation of state as a function of reduced pressure and temperature. In this work, for better calculation of solid solubility in supercritical phase, a new correction for energy parameter of RK EOS is proposed as a function of reduced temperature:

$$
P=\frac{R T}{v-b}-\frac{\beta a}{v(v+b)}
$$

In Eq. (8), $\beta$ is a correction that is written as follows:

$$
\beta_{i}=\frac{1+\beta_{i 1} T_{r}}{1-\beta_{i 2} T_{r}}
$$

In Eq. (9), $i$ belongs to $\mathrm{CO}_{2}$ or solid solute. Therefore, $\beta_{11}$ $\beta_{12}$ and $\beta_{21}-\beta_{22}$ are the parameters belonging to solute and $\mathrm{CO}_{2}$, respectively. In this investigation, two differences exist in comparison with the work of Heidaryan and Jarrahian [18]. First, the $\beta$ function includes two parameters for each compound in this work, but the $\beta$ function includes six parameters for each compound in the work of Heidaryan and Jarrahian [18]. The second difference is that they applied $\beta$ function in terms of reduced temperature and reduced pressure while in this work $\beta$ is only expressed in terms of reduced temperature. Therefore, not only our $\beta$ function is a new function but also our application is different and the proposed model is used for solubility calculation while Heidaryan and Jarrahian calculated the molar volume of supercritical $\mathrm{CO}_{2} . \beta_{11}-\beta_{12}$ and $\beta_{21}-\beta_{22}$ are determined based on the minimization of average absolute relative deviation percent (AARD\%), expressed by the following equation:

$$
A A R D=\frac{100}{N} \sum_{i} \frac{\left|y_{i}^{\exp }-y_{i}^{c a l}\right|}{y_{i}^{\exp }}
$$

In order to optimize the model parameters, a non-linear optimization technique based on the Nelder-Mead simplex algorithm was applied. 
The Peng-Robinson equation of state (PR EoS) [19] was also considered to determine the fugacity of components in the fluid (supercritical) phase. The PR EoS is written as follows:

$$
P=\frac{R T}{v-b}-\frac{a}{v^{2}+2 b v-b^{2}}
$$

In Eq. (11), $a$ and $b$ show the energy and volume parameters, respectively. The parameters of the PR EoS are as follows:

$$
\begin{gathered}
a=0.45724 \frac{\left(R T_{c}\right)^{2}}{P_{c}} \alpha(T) \\
b=0.0778 \frac{R T_{c}}{P_{c}}
\end{gathered}
$$

In Eqs. (12) and (13), $v$ shows the molar volume and subscripts $c$ and $r$ indicate the critical and reduced properties, respectively.

The $\alpha(T)$ parameter of PR EOS, is expressed as follows:

$$
\begin{gathered}
\alpha(T)=\left(1+m\left(1-T_{r}^{0.5}\right)\right)^{2} \\
m=0.37464+1.54226 \omega-0.26992 \omega^{2}
\end{gathered}
$$

In Eqs. (14) and (15), $\omega$ is the acentric factor that represented the acentricity or nonsphericity of a molecule with respect to both the geometry and polarity [29].

In this investigation, the PR-EOS is combined with van der Waals one (vdW1) and Wong-Sandler (WS) mixing rules.

The van der Waals mixing rule can be written as follows:

$$
\begin{gathered}
a_{m}=\sum_{i} \sum_{j} a_{i j} x_{i} x_{j} \\
a_{i j}=\sqrt{a_{i} a_{j}}\left(1-k_{i j}\right) \\
b_{m}=\sum_{i} b_{i} y_{i}
\end{gathered}
$$

In Eq. (17), if $k_{i j}$ is set equal to zero, the mixing rule is named vdW0 instead of vdW1 mixing rule.

The Wong Sandler mixing rule can be expressed as follows:

$$
\begin{gathered}
b_{m}=\frac{Q}{1-D} \\
a_{m}=R T D b_{m}
\end{gathered}
$$

In Eqs. (19) and (20):

$$
\begin{gathered}
Q=\sum_{i} \sum_{j} x_{i} x_{j}\left(a-\frac{b}{R T}\right)_{i j} \\
D=\sum_{i} \frac{y_{i} a_{i}}{b_{i} R T}+\frac{G^{E}}{\Omega R T}
\end{gathered}
$$

In Eq. (21):

$$
\left(a-\frac{b}{R T}\right)_{i j}=\left[b_{i}-\frac{a_{i}}{R T}+b_{j}-\frac{a_{j}}{R T}\right]\left(\frac{1-k_{i j}}{2}\right)
$$

In this paper, the van-Laar activity model is chosen to calculate the excess Gibbs energy in Eq. (22).

\section{Results and discussion}

In this modeling investigation, the solubilities of tweny solid components containing Ascorbic acid, Fluoranthene, Propyl gallate, Acenaphthene, Asprin, Climbazole, Cinnamic acid, Triclocarban, 4-methoxyphenylacetic acid, Phenoxyacetic acid, Cholesterol, Cholesteryl butyrate, Cholestrol acetat,Triphenylene, Ibuprofen, Acetanilide, Propanamide, Butanamide, Chrysene and Dodecyl gallate in supercritical carbon dioxide have been calculated. The experimental solubilities were obtained from the literature [10,20-28]. To reproduce the solid solubility in supercritical carbon dioxide, the Peng Robinson equation of state (PR EOS) has been applied in combination with the van der Waals (vdW1) and Wong Sandler (WS) mixing rules. In order to determine the parameters of van der Waals (vdW1) and Wong Sandler (WS) mixing rules (i.e. binary interaction parameter), the parameters have been determined by a minimization program. The average absolute relative deviations (AARD\%) and the determined parameters for the applied models including PR-vdW1, PR-WS and $\beta R K-v d W 0$ models have been reported in Table 2. Figs. 1 and 2 compare the results of PR-vdW1, PR-WS and $\beta R K-v d W 0$ models with the experimental solubilities of acenaphthene and chrysene in supercritical $\mathrm{CO}_{2}$, respectively. It can be concluded that the WS mixing rule is much more accurate than vdW1 mixing rule so that the PR EOS in combination with the WS mixing rule performs more accurately for modeling the solubilities of these solids in supercritical carbon dioxide.

In order to reveal the precision of the proposed EoS ( $\beta R \mathrm{R}$ EoS) combining with the simple vdW0 mixing rule, the proposed model has been used to reproduce the solubilities of these twenty solid components in supercritical carbon dioxide. The accuracy of the proposed model and the parameters of the proposed model have been presented in Table 2. One can see in Table 2 that the proposed model performs much more accurately than the Peng-Robinson EoS and vdW1 mixing rule, even it is better than the couple of PR-EoS and WS mixing rule. By considering the results of the applied models, it can be concluded that the $\beta \mathrm{RK}$ is able to reproduce the solubilities of these twenty solid components in supercritical carbon dioxide. This model does not need any complicated mixing rule so that combination of $\beta \mathrm{RK}$ and the simple mixing rule of vdW0 is a reliable approach of computing the phase equilibrium of (solid + supercritical carbon dioxide) systems. 
Table 2 The parameters and AARD (\%) of applied models in this work

\begin{tabular}{|c|c|c|c|c|c|c|c|c|c|c|}
\hline \multirow{3}{*}{ Compound } & \multirow{3}{*}{$\mathbf{T}(\mathbf{k})$} & \multirow{3}{*}{ P(MPa) } & \multirow{3}{*}{$\mathbf{N D}^{\mathrm{a}}$} & \multirow{3}{*}{$\operatorname{Ref}^{b}$} & \multirow{3}{*}{ Models } & \multicolumn{4}{|c|}{ Model parameter } & \multirow{3}{*}{$\begin{array}{c}\text { AARD }^{\mathrm{c}} \\
(\%)\end{array}$} \\
\hline & & & & & & \multirow{2}{*}{$\begin{array}{l}\text { Kij } \\
\beta_{11} \\
\end{array}$} & \multirow{2}{*}{$\begin{array}{l}\text { Aij } \\
\beta_{12} \\
\end{array}$} & \multicolumn{2}{|l|}{ Aji } & \\
\hline & & & & & & & & $\boldsymbol{\beta}_{21}$ & $\beta_{22}$ & \\
\hline \multirow{3}{*}{ 1. Ascorbic acid } & \multirow{3}{*}{313} & \multirow{3}{*}{$13-20$} & \multirow{3}{*}{4} & \multirow{3}{*}[21]{} & PR-vdW1 ${ }^{\mathrm{D}}$ & 0.4692 & - & - & - & 11.16 \\
\hline & & & & & PR-WS & 0.8831 & -0.0888 & 21.3486 & - & 2.3 \\
\hline & & & & & $\beta R K-v d W 0^{F}$ & 0.1907 & 2.4727 & -1.0096 & -9.5896 & 0.217 \\
\hline \multirow{9}{*}{ 2. fluoranthene } & \multirow{3}{*}{308.15} & \multirow{3}{*}{$8.9-24.7$} & \multirow{3}{*}{12} & \multirow{3}{*}{ [23] } & PR-vdW1 & 0.12 & - & - & - & 5.5 \\
\hline & & & & & PR-WS & 0.7893 & 1.5690 & 7.2349 & - & 4.47 \\
\hline & & & & & $\beta R K-v d W 0$ & 1.89 & 0.7272 & -0.0041 & 0.25 & 3.84 \\
\hline & \multirow{3}{*}{318.15} & \multirow{3}{*}{$9-24.9$} & \multirow{3}{*}{9} & \multirow{3}{*}[23]{} & PR-vdW1 & 0.1148 & - & - & - & 16.3 \\
\hline & & & & & PR-WS & 0.7785 & 0.0953 & 8.8956 & - & 8.5 \\
\hline & & & & & $\beta R K-v d W 0$ & 2.3550 & 0.0105 & -0.0357 & -0.3184 & 7.1 \\
\hline & \multirow{3}{*}{328.15} & & & & PR-vdW1 & 0.1060 & - & - & - & 5.6 \\
\hline & & $12.1-20.9$ & 5 & [23] & PR-WS & 0.7940 & 1.6033 & 5.3485 & - & 5.3 \\
\hline & & & & & $\beta R K-v d W 0$ & 2.3021 & 0.1149 & -0.0741 & -0.1923 & 5.43 \\
\hline & & & & & PR-vdW1 & 0.2430 & - & - & - & 5.41 \\
\hline & 313.15 & $15-25$ & 4 & [21] & PR-WS & 0.7546 & -4.5518 & 11.9579 & & 0.62 \\
\hline & & & & & $\beta R K-v d W 0$ & 15.0493 & -0.1158 & -2.2806 & 2.4304 & 0.14 \\
\hline 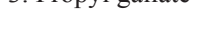 & & & & & PR-vdW1 & 0.22787 & - & - & - & 13.03 \\
\hline & 333.15 & $15-25$ & 4 & [21] & PR-WS & 0.7407 & -3.1512 & 11.3529 & - & 2.47 \\
\hline & & & & & $\beta R K-v d W 0$ & 8.4990 & -0.3624 & 0.3298 & 2.7554 & 0.68 \\
\hline & 308.15 & $12.1-35.5$ & 9 & {$[25]$} & PR-vdW1 & -0.2284 & - & - & - & 27 \\
\hline & 308.15 & $121-35.5$ & 9 & {$[25]$} & PR-WS & 0.5351 & -2.5321 & -6.6329 & - & 9.5 \\
\hline & & & & & $\beta R K$-vdW0 & 5.0797 & -0.3487 & 0.1060 & 0.1404 & 3.73 \\
\hline & & & & & PR-vdW1 & -0.2421 & - & - & - & 32 \\
\hline & 318.15 & $12.1-35.5$ & 9 & {$[25]$} & PR-WS & 0.5445 & -0.2320 & -9.2907 & - & 10.9 \\
\hline & & & & & $\beta R K-v d W 0$ & 3.8617 & 0.2699 & 0.1103 & -0.1714 & 2.9 \\
\hline & & & & & PR-vdW1 & -0.2488 & - & - & - & 39 \\
\hline 4. acenaphthene & 328.15 & $12.1-35.5$ & 9 & [25] & PR-WS & 0.4827 & -0.1273 & -7.0662 & - & 12.4 \\
\hline & & & & & $\beta R K-v d W 0$ & 2.8263 & 0.7004 & 0.0850 & 0.1849 & 3.7 \\
\hline & & & & & PR-vdW1 & -0.2798 & - & - & - & 43 \\
\hline & 338.15 & $12.1-35.5$ & 9 & {$[25]$} & PR-WS & 0.4530 & -0.1915 & -6.4648 & - & 15.1 \\
\hline & & & & & $\beta R K-v d W 0$ & 3.6189 & 0.1976 & 0.1055 & -0.5609 & 0.9 \\
\hline & & & & & PR-vdW1 & -0.3047 & - & - & - & 48 \\
\hline & 348.15 & $12.1-35.5$ & 9 & {$[25]$} & PR-WS & 0.4185 & -0.1681 & -5.2579 & - & 16.7 \\
\hline & & & & & $\beta R K-v d W 0$ & 3.0085 & 0.4589 & 0.0503 & 0.1117 & 4.4 \\
\hline
\end{tabular}

${ }^{\mathrm{a}}$ number of data , ${ }^{\mathrm{b}}$ reference, ${ }^{\mathrm{c}}$ the average absolute relative deviation between experimental data and calculation results, ${ }^{\mathrm{D}}$ Peng Robinson equation of state with van der Waals one mixing rules, ${ }^{\mathrm{E}}$ Robinson equation of state with Wong-Sandler mixing rules, ${ }^{\mathrm{F}}$ modified Redlich-Kwong with van der Waals zero mixing rules (proposed model) 
Table 2 (Continued)

\begin{tabular}{|c|c|c|c|c|c|c|c|c|c|c|}
\hline \multirow{3}{*}{ Compound } & \multirow{3}{*}{$\mathbf{T}(\mathbf{k})$} & \multirow{3}{*}{$\mathbf{P}(\mathbf{M P a})$} & \multirow{3}{*}{$\mathbf{N D}^{\mathbf{a}}$} & \multirow{3}{*}{$\operatorname{Ref}^{b}$} & \multirow{3}{*}{ Models } & \multicolumn{4}{|c|}{ Model parameter } & \multirow{3}{*}{$\begin{array}{c}\text { AARD }^{\mathrm{c}} \\
(\%)\end{array}$} \\
\hline & & & & & & \multirow{2}{*}{$\begin{array}{c}\mathbf{K i j} \\
\beta_{11}\end{array}$} & \multirow{2}{*}{$\begin{array}{c}\text { Aij } \\
\beta_{12}\end{array}$} & \multicolumn{2}{|l|}{$\mathbf{A j i}$} & \\
\hline & & & & & & & & $\beta_{21}$ & $\boldsymbol{\beta}_{22}$ & \\
\hline \multirow{9}{*}{ 5.Asprin } & \multirow{3}{*}{308.15} & \multirow{3}{*}{$12-25$} & \multirow{3}{*}{8} & \multirow{3}{*}[22]{} & PR-vdW1 & 0.216 & - & - & - & 2.32 \\
\hline & & & & & PR-WS & 0.7676 & 0.7179 & 8.8559 & & 1.21 \\
\hline & & & & & $\beta R K-v d W 0$ & -16.043 & 0.2868 & -2.2806 & -0.1732 & 2.47 \\
\hline & \multirow{3}{*}{318.15} & \multirow{3}{*}{$12-25$} & \multirow{3}{*}{8} & \multirow{3}{*}[22]{} & PR-vdW1 & 0.2112 & - & - & - & 7.39 \\
\hline & & & & & PR-WS & 0.7769 & 1.2229 & 7.5078 & - & 2.38 \\
\hline & & & & & $\beta R K-v d W 0$ & -16.112 & 0.2009 & -2.1150 & -0.1367 & 1.31 \\
\hline & \multirow{3}{*}{328.15} & \multirow{3}{*}{$12-25$} & \multirow{3}{*}{8} & \multirow{3}{*}[22]{} & PR-vdW1 & 0.209 & - & - & - & 8.7 \\
\hline & & & & & PR-WS & 0.7692 & 0.1453 & 7.9679 & - & 4.35 \\
\hline & & & & & $\beta R K-v d W 0$ & -13.119 & 0.4986 & -1.1072 & 0.3496 & 5.75 \\
\hline & & & & & PR-vdW1 & 0.1480 & - & - & - & 10.49 \\
\hline & 313.2 & $10.5-40$ & 8 & {$[24]$} & PR-WS & 0.8137 & 2.0944 & 8.6670 & - & 5.3 \\
\hline & & & & & $\beta R K-v d W 0$ & 2.5621 & 0.2623 & -0.0277 & 0.0736 & 7.6 \\
\hline & & & & & PR-vdW1 & 0.1542 & - & - & - & 5.17 \\
\hline 6. Climbazole & 323.2 & $13-36.5$ & 8 & {$[24]$} & PR-WS & 0.7769 & 1.2229 & 7.5078 & - & 2.38 \\
\hline & & & & & $\beta R K-v d W 0$ & 2.2565 & 0.3343 & -0.0521 & 0.0657 & 6.4 \\
\hline & & & & & PR-vdW1 & 0.1594 & - & - & - & 5.87 \\
\hline & 333.2 & $14.5-35.5$ & 8 & {$[24]$} & PR-WS & 0.8196 & 1.0461 & 8.6648 & - & 1.4 \\
\hline & & & & & $\beta R K-v d W 0$ & 2.0541 & 0.3902 & -0.0760 & 0.1135 & 3.89 \\
\hline & & & & & PR-vdW1 & 0.0274 & - & - & - & 4.9 \\
\hline & 308.2 & $15-23$ & 4 & [20] & PR-WS & 0.6467 & 0.0051 & 4.5907 & - & 4.95 \\
\hline & & & & & $\beta R K-v d W 0$ & 2.6560 & 0.6394 & -0.0255 & 0.0348 & 4.1 \\
\hline & & & & & PR-vdW1 & 0.0288 & - & - & - & 10.8 \\
\hline 7. Cinnamic acid & 318.2 & $12-23$ & 7 & {$[20]$} & PR-WS & 0.7013 & 0.7778 & 0.1893 & - & 8.96 \\
\hline & & & & & $\beta R K-v d W 0$ & 2.9771 & 0.3035 & -0.0728 & -0.2576 & 3.2 \\
\hline & & & & & PR-vdW1 & 0.0296 & - & - & - & 3 \\
\hline & 3282 & $14.5-23.5$ & 6 & {$[20]$} & PR-WS & 0.6840 & 0.5619 & 1.3847 & - & 2 \\
\hline & & & & & $\beta R K-v d W 0$ & 3.2057 & -0.1603 & -0.0989 & -0.6008 & 1.7 \\
\hline & & & & & PR-vdW1 & 0.1955 & - & - & - & 15.16 \\
\hline & 313.2 & $10.9-39$ & 8 & {$[24]$} & PR-WS & 0.7962 & -0.5928 & 10.2380 & - & 2.037 \\
\hline & & & & & $\beta R K-v d W 0$ & 3.1083 & 2.4722 & -0.0105 & 0.0325 & 3.1 \\
\hline & & & & & PR-vdW1 & 0.1944 & - & - & - & 16.44 \\
\hline 8. triclocarban & 323.2 & $12-33.3$ & 8 & {$[24]$} & PR-WS & 0.7953 & 7.9431 & 10.4874 & - & 5.22 \\
\hline & & & & & $\beta R K-v d W 0$ & 3.1225 & 2.3595 & -0.0307 & 0.0309 & 5.01 \\
\hline & 333.2 & $13.7-30.5$ & 8 & [24] & PR-vdW1 & 0.2047 & - & - & - & 11.93 \\
\hline & & & & & PR-WS & 0.7987 & -10.927 & 10.3580 & - & 1.01 \\
\hline & 535.2 & $15.1-20.2$ & 0 & {$[2-1]$} & $\beta \mathrm{RK}-\mathrm{vdW0}$ & 3.0913 & 2.2582 & -0.0545 & 0.0316 & 1.47 \\
\hline
\end{tabular}




\begin{tabular}{|c|c|c|c|c|c|c|c|c|c|c|}
\hline \multirow{3}{*}{ Compound } & \multirow{3}{*}{$\mathbf{T}(\mathbf{k})$} & \multirow{3}{*}{$\mathbf{P}(\mathbf{M P a})$} & \multirow{3}{*}{ ND $^{\mathbf{a}}$} & \multirow{3}{*}{$\operatorname{Ref}^{b}$} & \multirow{3}{*}{ Models } & \multicolumn{4}{|c|}{ Model parameter } & \multirow{3}{*}{$\begin{array}{l}\text { AARD }^{c} \\
(\%)\end{array}$} \\
\hline & & & & & & Kij & Aij & Aji & & \\
\hline & & & & & & $\beta_{11}$ & $\beta_{12}$ & $\beta_{21}$ & $\beta_{22}$ & \\
\hline \multirow{9}{*}{$\begin{array}{l}\text { 9. 4-methoxyphenylacetic } \\
\text { acid }\end{array}$} & \multirow{3}{*}{308.2} & \multirow{3}{*}{$11.5-24$} & \multirow{3}{*}{7} & \multirow{3}{*}{ [20] } & PR-vdW1 & -0.1298 & - & - & - & 16.4 \\
\hline & & & & & PR-WS & 0.6363 & 1.8589 & -3.3767 & - & 3.8 \\
\hline & & & & & $\beta R K-v d W 0$ & 52.0292 & -1.6455 & 0.0161 & 0.4433 & 4.1 \\
\hline & \multirow{3}{*}{318.2} & \multirow{3}{*}{$12.5-23$} & \multirow{3}{*}{8} & \multirow{3}{*}{ [20] } & PR-vdW1 & -0.1351 & - & - & - & 13.8 \\
\hline & & & & & PR-WS & 0.6394 & 2.3698 & -3.2314 & & 3 \\
\hline & & & & & $\beta R K-v d W 0$ & 112.7861 & -6.8023 & 0.0296 & 3.9067 & 3.2 \\
\hline & \multirow{3}{*}{328.2} & \multirow{3}{*}{$14-23.5$} & \multirow{3}{*}{7} & \multirow{3}{*}{ [20] } & PR-vdW1 & -0.1375 & - & - & - & 8.8 \\
\hline & & & & & PR-WS & 0.6547 & 0.2993 & -3.9677 & - & 4.1 \\
\hline & & & & & $\beta R K-v d W 0$ & 109.9834 & -6.8570 & 0.0244 & 1.5701 & 3.9 \\
\hline \multirow{9}{*}{ 10. phenoxyacetic acid } & \multirow{3}{*}{308.2} & \multirow{3}{*}{$12-22$} & & & PR-vdW1 & -0.1298 & - & - & - & 16.4 \\
\hline & & & 7 & [20] & PR-WS & 0.7503 & 0.7516 & 4.5344 & - & 3.8 \\
\hline & & & & & $\beta R K-v d W 0$ & 41.7481 & -3.6182 & -0.2508 & -4.3556 & 2.7 \\
\hline & & & & & PR-vdW1 & -0.1351 & - & - & - & 13.8 \\
\hline & 318.2 & $12-22$ & 7 & [20] & PR-WS & 0.7502 & 0.7288 & 4.5434 & - & 3.37 \\
\hline & & & & & $\beta R K-v d W 0$ & 40.5517 & -3.6971 & -0.3499 & -3.9642 & 2.9 \\
\hline & & & & & PR-vdW1 & 0.1489 & - & - & - & 9.7 \\
\hline & 328.2 & $12-22$ & 8 & [20] & PR-WS & 0.7474 & 0.8288 & 4.4401 & - & 4.1 \\
\hline & & & & & $\beta R K-v d W 0$ & 40.7857 & -4.0229 & -0.3899 & -3.5015 & 3.4 \\
\hline & & & & & PR-vdW1 & 0.4911 & - & - & - & 8.5 \\
\hline & 313.15 & $10-25$ & 6 & [26] & PR-WS & 0.9026 & 0.5515 & 35.8405 & - & 9 \\
\hline & & & & & $\beta R K-v d W 0$ & -0.2195 & 1.6612 & 0.0001 & 0.9736 & 3 \\
\hline & & & & & PR-vdW1 & 0.5032 & - & - & - & 44 \\
\hline 11. Cholesterol & 323.15 & $10-25$ & 6 & [26] & PR-WS & 0.9322 & -7.5416 & 30.2097 & - & 24 \\
\hline & & & & & $\beta R K-v d W 0$ & $-7.8 \mathrm{E}-6$ & 3.6151 & $1.969 \mathrm{E}-5$ & 0.94153 & 17.7 \\
\hline & & & & & PR-vdW1 & 0.5093 & - & - & - & 35.4 \\
\hline & 333.15 & $13-25$ & 5 & [26] & PR-WS & 0.9340 & 5.0424 & 28.9155 & - & 17.2 \\
\hline & & & & & $\beta R K-v d W 0$ & -0.4956 & 0.0407 & -0.4350 & -1.6693 & 12.5 \\
\hline & & & & & PR-vdW1 & 0.4353 & - & - & - & 21 \\
\hline & 308.15 & $10-24$ & 7 & [27] & PR-WS & 0.9067 & 58.1398 & 37.0256 & - & 12.35 \\
\hline & & & & & $\beta R K-v d W 0$ & 0.6280 & -0.2244 & -0.0252 & -0.2409 & 12.6 \\
\hline & & & & & PR-vdW1 & 0.4439 & - & - & - & 18.6 \\
\hline 12. cholesteryl butyrate & 318.15 & $10-24$ & 7 & [27] & PR-WS & 0.9114 & 579.2555 & 35.1620 & - & 14 \\
\hline & & & & & $\beta R K-v d W 0$ & 0.4311 & 0.2463 & -0.0585 & -0.0605 & 7.5 \\
\hline & & & & & PR-vdW1 & 0.4553 & - & - & - & 17.6 \\
\hline & 328.15 & $12-24$ & 6 & [27] & PR-WS & 0.9185 & 79.1976 & 33.3959 & - & 11.6 \\
\hline & & & & & $\beta R K-v d W 0$ & 0.2306 & 0.1524 & -0.1070 & -0.2988 & 6.9 \\
\hline
\end{tabular}


Table 2 (Continued)

\begin{tabular}{|c|c|c|c|c|c|c|c|c|c|c|}
\hline \multirow{3}{*}{ Compound } & \multirow{3}{*}{$\mathbf{T}(\mathbf{k})$} & \multirow{3}{*}{$\mathbf{P}(\mathbf{M P a})$} & \multirow{3}{*}{$\mathbf{N D}^{\mathrm{a}}$} & \multirow{3}{*}{$\operatorname{Ref}^{b}$} & \multirow{3}{*}{ Models } & \multicolumn{4}{|c|}{ Model parameter } & \multirow{3}{*}{$\begin{array}{c}\text { AARD }^{c} \\
(\%)\end{array}$} \\
\hline & & & & & & \multirow{2}{*}{$\begin{array}{c}\mathbf{K i j} \\
\beta_{11}\end{array}$} & \multirow{2}{*}{$\begin{array}{l}\mathrm{Aij} \\
\beta_{12}\end{array}$} & \multicolumn{2}{|l|}{ Aji } & \\
\hline & & & & & & & & $\boldsymbol{\beta}_{21}$ & $\boldsymbol{\beta}_{22}$ & \\
\hline \multirow{9}{*}{ 13. cholestrol acetat } & \multirow{3}{*}{308.15} & \multirow{3}{*}{$9-24$} & \multirow{3}{*}{8} & \multirow{3}{*}[27]{} & PR-vdW1 & 0.412824 & - & - & - & 20.27 \\
\hline & & & & & PR-WS & 0.8876 & -495.129 & 32.5868 & - & 5.9 \\
\hline & & & & & $\beta R K-v d W 0$ & 0.6013 & -0.2888 & -0.0014 & -0.3520 & 6.8 \\
\hline & \multirow{3}{*}{318.15} & \multirow{3}{*}{$9-24$} & \multirow{3}{*}{9} & \multirow{3}{*}{ [27] } & PR-vdW1 & 0.42260 & - & - & - & 17.66 \\
\hline & & & & & PR-WS & 0.9 & 1542.2 & 29.4 & - & 14.5 \\
\hline & & & & & $\beta R K-v d W 0$ & 0.4778 & -0.2843 & -0.0488 & -0.0859 & 10.8 \\
\hline & \multirow{3}{*}{328.15} & \multirow{3}{*}{$9-21$} & \multirow{3}{*}{7} & \multirow{3}{*}[27]{} & PR-vdW1 & 0.4312 & - & - & - & 37.66 \\
\hline & & & & & PR-WS & 0.9177 & -117.823 & 24.0926 & - & 13.3 \\
\hline & & & & & $\beta R K-v d W 0$ & 0.2960 & 1.8023 & -0.0946 & 0.0662 & 9.2 \\
\hline & & & & & PR-vdW1 & 0.0874 & - & - & - & 22 \\
\hline & 308.15 & $8.5-24.7$ & 10 & [23] & PR-WS & 0.7766 & 0.1093 & 7.0432 & - & 10.4 \\
\hline & & & & & $\beta R K-v d W 0$ & 3.0380 & -0.0567 & 0.0126 & -0.0829 & 3.8 \\
\hline & & & & & PR-vdW1 & 0.0797 & - & - & - & 29 \\
\hline 14. Triphenylene & 318.15 & $9.6-25.2$ & 10 & [23] & PR-WS & 0.7681 & -57.3892 & 7.8926 & & 8.9 \\
\hline & & & & & $\beta R K-v d W 0$ & 2.6831 & 0.1899 & -0.0186 & -0.4474 & 7.5 \\
\hline & & & & & PR-vdW1 & 0.0776 & - & - & - & 24 \\
\hline & 328.15 & $10.7-25.1$ & 8 & [23] & PR-WS & 0.7751 & -60.7706 & 6.6758 & - & 8.7 \\
\hline & & & & & $\beta R K$-vdW0 & 78.0323 & -86.8448 & -0.00001 & 0.9267 & 3.5 \\
\hline & & & & & PR-vdW1 & 0.0873 & - & - & - & 23 \\
\hline & 308.15 & $8-13$ & 11 & [11] & PR-WS & 0.7847 & 0.8483 & 2.4358 & - & 15.6 \\
\hline & & & & & $\beta R K-v d W 0$ & -18.9573 & 0.3299 & -2.2443 & -0.1455 & 9.1 \\
\hline & & & & & PR-vdW1 & 0.0757 & - & - & - & 14.8 \\
\hline 15. Ibuprofen & 313.15 & $9-13$ & 9 & {$[11]$} & PR-WS & 0.7824 & 0.7263 & 1.7011 & - & 6.5 \\
\hline & & & & & $\beta R K-v d W 0$ & -19.0053 & 0.2821 & -2.2414 & -0.1660 & 8.5 \\
\hline & & & & & PR-vdW1 & 0.0875 & - & - & - & 28 \\
\hline & 318.15 & $8-13$ & 11 & {$[11]$} & PR-WS & 0.7893 & 0.5901 & 0.3562 & - & 8.7 \\
\hline & & & & & $\beta R K-v d W 0$ & -18.7651 & 0.2793 & -2.1858 & -0.1650 & 7.9 \\
\hline & & & & & PR-vdW1 & 0.3136 & - & - & - & 70 \\
\hline & 308.2 & $9-40$ & 10 & [28] & PR-WS & 0.8198 & -6.3799 & 4.6974 & - & 34 \\
\hline & & & & & $\beta R K-v d W 0$ & 0.8266 & 0.4058 & -0.1172 & 0.0030 & 5.7 \\
\hline & & & & & PR-vdW1 & 0.3260 & - & - & - & 68 \\
\hline 16. Acetanilide & 313.2 & $9-40$ & 10 & [28] & PR-WS & 0.8013 & -1.6914 & 4.2210 & - & 19.2 \\
\hline & & & & & $\beta R K$-vdW0 & 0.9953 & 0.2535 & -0.1491 & -0.0214 & 7.4 \\
\hline & & & & & PR-vdW1 & 0.2155 & - & - & - & 48.1 \\
\hline & 323.2 & $10-40$ & 9 & [28] & PR-WS & 0.7689 & -3.8279 & 4.9670 & - & 26 \\
\hline & & & & & $\beta R K-v d W 0$ & 1.0401 & -0.4126 & -0.1369 & -0.1348 & 18.8 \\
\hline
\end{tabular}


Table 2 (Continued)

\begin{tabular}{|c|c|c|c|c|c|c|c|c|c|c|}
\hline \multirow{3}{*}{ Compound } & \multirow{3}{*}{$\mathbf{T}(\mathbf{k})$} & \multirow{3}{*}{$\mathbf{P}(\mathbf{M P a})$} & \multirow{3}{*}{$\mathbf{N D}^{\mathbf{a}}$} & \multirow{3}{*}{$\operatorname{Ref}^{b}$} & \multirow{3}{*}{ Models } & \multicolumn{4}{|c|}{ Model parameter } & \multirow{3}{*}{$\begin{array}{c}\text { AARD }^{\mathrm{c}} \\
(\%)\end{array}$} \\
\hline & & & & & & \multirow{2}{*}{$\begin{array}{c}\mathrm{Kij} \\
\boldsymbol{\beta}_{11}\end{array}$} & \multirow{2}{*}{$\frac{A i j}{\beta_{12}}$} & \multicolumn{2}{|l|}{$\mathbf{A j i}$} & \\
\hline & & & & & & & & $\beta_{21}$ & $\boldsymbol{\beta}_{22}$ & \\
\hline \multirow{9}{*}{ 17. Propanamide } & \multirow{3}{*}{308.2} & \multirow{3}{*}{$9-40$} & \multirow{3}{*}{10} & \multirow{3}{*}[28]{} & PR-vdW1 & 0.1392 & - & - & - & 6.7 \\
\hline & & & & & PR-WS & 0.6288 & 0.3821 & 4.3651 & - & 4.2 \\
\hline & & & & & $\beta R K-v d W 0$ & 1.6992 & -0.5152 & -0.0305 & -0.2956 & 5.6 \\
\hline & \multirow{3}{*}{313.2} & \multirow{3}{*}{$9-40$} & \multirow{3}{*}{10} & \multirow{3}{*}[28]{} & PR-vdW1 & 0.1404 & - & - & - & 5.8 \\
\hline & & & & & PR-WS & 0.6129 & 0.8504 & 4.4979 & & 5.1 \\
\hline & & & & & $\beta R K-v d W 0$ & 1.4258 & -0.6370 & -0.0257 & -0.2734 & 4.9 \\
\hline & \multirow{3}{*}{323.2} & \multirow{3}{*}{$10-40$} & \multirow{3}{*}{10} & \multirow{3}{*}[28]{} & PR-vdW1 & 0.1376 & - & - & - & 21.4 \\
\hline & & & & & PR-WS & 0.5929 & 64.5507 & 4.7321 & - & 14.4 \\
\hline & & & & & $\beta R K-v d W 0$ & 1.5906 & -0.5278 & -0.0284 & -0.2891 & 13.3 \\
\hline \multirow{9}{*}{ 18. Butanamide } & \multirow{3}{*}{308.2} & \multirow{3}{*}{$9-40$} & \multirow{3}{*}{10} & \multirow{3}{*}[28]{} & PR-vdW1 & 0.1487 & & & & 7.4 \\
\hline & & & & & PR-WS & 0.6408 & 2.2683 & 4.5660 & & 7.2 \\
\hline & & & & & $\beta R K-v d W 0$ & 1.6144 & -0.5244 & -0.0290 & -0.2902 & 6.1 \\
\hline & & & & & PR-vdW1 & 0.1398 & & & & 10.5 \\
\hline & 313.2 & $9-40$ & 10 & {$[28]$} & PR-WS & 0.6475 & -2.5151 & 4.0516 & & 10.4 \\
\hline & & & & & $\beta R K-v d W 0$ & 1.5155 & -0.6062 & -0.0213 & -0.2840 & 9.5 \\
\hline & & & & & PR-vdW1 & 0.1402 & & & & 10.2 \\
\hline & 323.2 & $10-40$ & 10 & {$[28]$} & PR-WS & 0.6270 & -1.6628 & 4.1685 & & 74 \\
\hline & & & & & $\beta R K-v d W 0$ & 1.5625 & -0.6371 & -0.0537 & -0.2405 & 7.9 \\
\hline & & & & & PR-vdW1 & 0.1020 & - & - & - & 16.2 \\
\hline 19. Chrysene & 308.15 & $8.4-25.1$ & 11 & {$[23]$} & PR-WS & 0.7878 & 7.3497 & 7.3190 & & 8.1 \\
\hline & & & & & $\beta R K-v d W 0$ & 2.8767 & 0.0484 & 0.0008 & -0.2020 & 4.2 \\
\hline & & & & & PR-vdW1 & 0.0253 & - & - & - & 14.1 \\
\hline 20. Dodecyl gallate & 313.1 & $15-25$ & 4 & {$[21]$} & PR-WS & 0.7561 & 4.2943 & 4.0208 & - & 4 \\
\hline & & & & & $\beta R K-v d W 0$ & 3.8443 & -0.0718 & 0.0320 & -0.4279 & 2.7 \\
\hline & & & & & & & PR-vdW1 & & & 19.4 \\
\hline Total AARD(\%) & $308-348$ & $8-40$ & 440 & & & & PR-WS & & & 9.6 \\
\hline & & & & & & & $\beta R K-v d W 0$ & & & 5.7 \\
\hline
\end{tabular}




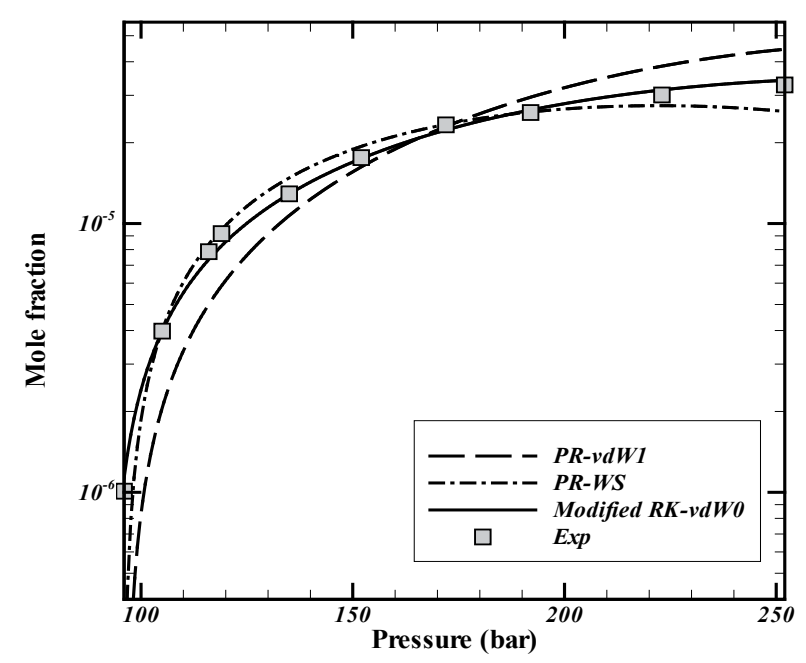

Fig. 1 Experimental and calculated solubilities of acenaphthene in supercritical $\mathrm{CO}_{2}$ at $T=318.15 \mathrm{~K}$

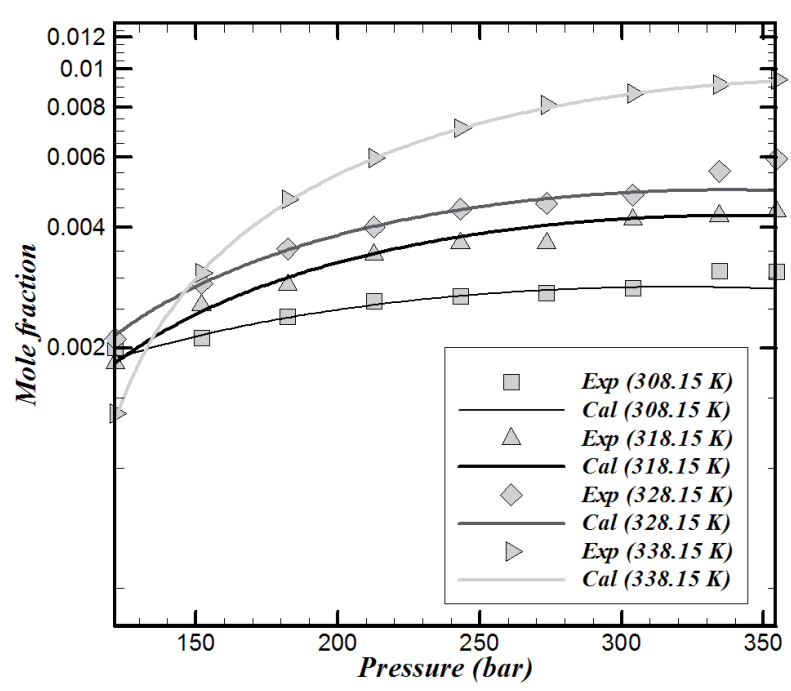

Fig. 3 Experimental and calculated solubilities of Acenaphthene in supercritical $\mathrm{CO}_{2}$ at different isotherms.

Figure 3 demonstrates the solubilities for Acenaphthene at different isotherms using the proposed model. Also Fig. 4 shows the calculated solubilities versus experimental solubilities for all of 440 points. The close points to solid line show the accurate performance of the applied model so that it is found that the proposed model is able to reproduce the solubility of solids in the SC-CO2 with an acceptable deviation.

\section{Conclusion}

A new modified RK equation of state ( $\beta$ RK-EoS) combined with the vdW0 mixing rule proposed to reproduce the solubilities of twenty solids in supercritical carbon dioxide. The parameters of the model have been determined and reported. Additionally, the results of this proposed model have been compared with the PR EoS-VdW1 and PR EoS-WS models. It is found that the relative error (AARD\%) between the calculation

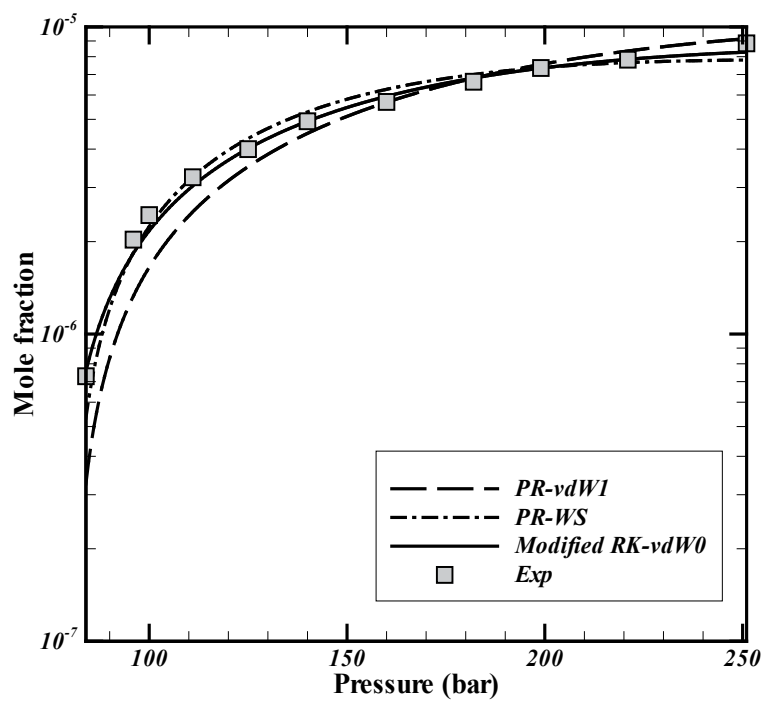

Fig. 2 Experimental and calculated solubilities of Chrysene in supercritical $\mathrm{CO}_{2}$ at $T=308.15 \mathrm{~K}$

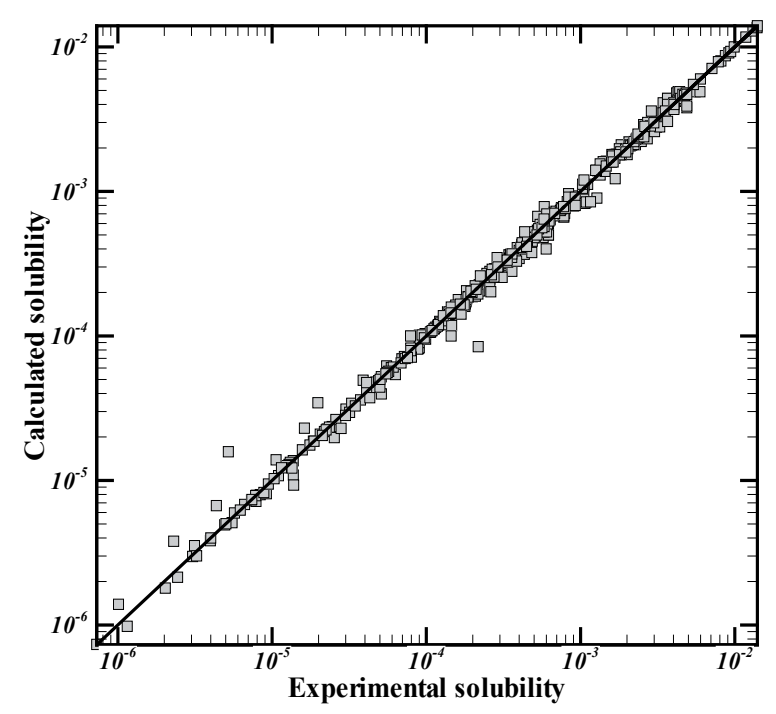

Fig. 4 The calculated solubilities versus experimental solubilities for all of 440 points

results and the experimental data for the proposed model is $5.7 \%$. The results showed that the proposed model performs more accurate than PR EOS-VdW1 and PR EOS-WS models.

\section{Nomenclature}

$A_{i j}, A_{j i} \quad$ parameters used in WS mixing rules

a attraction parameter

$\mathrm{a}_{\mathrm{m}} \quad$ attraction parameter of the supercritical solution

AARD $\% \quad$ average absolute relative deviation (\%)

$b \quad$ co-volume parameter

$\mathrm{b}_{\mathrm{m}} \quad$ co-volume parameter of the supercritical solution

EoSs equation of states

$f_{i} \quad$ fugacity of component $\mathrm{i}$

$k_{i j} \quad$ binary intraction parameter 


$\begin{array}{ll}P & \text { ressure } \\ \text { PR } & \text { Peng-Robinson } \\ R & \text { universal gas constant } \\ \text { RK } & \text { Redlich-Kwong } \\ T & \text { temperature } \\ V & \text { volume } \\ \text { vdW } & \text { van der Waals } \\ y_{i} & \text { mole fraction of component i }\end{array}$

\section{Greek symbols}

$\begin{array}{ll}\alpha & \begin{array}{l}\text { temperature-dependent parameter for } \\ \text { calculation of } \mathrm{a}(\mathrm{T})\end{array} \\ \beta & \text { coefficients of proposed EoS } \\ \beta R K & \text { modified Redlich-Kwong EoS } \\ \varphi & \text { fugacity coefficient }\end{array}$

\section{Subscripts}

$\begin{array}{ll}\text { c } & \text { critical point } \\ i & \text { belongs to } \mathrm{CO} 2 \text { or solid solute }\end{array}$

\section{Superscripts}

$\begin{array}{ll}s & \text { solid phase } \\ \text { sat } & \text { saturation } \\ \text { cal } & \text { calculated } \\ \exp & \text { experimental }\end{array}$

\section{References}

[1] Cheng, S. H., Yang, F. C., Yang, Y. H., Hu, C. C., Chang, W. T. "Measurements and modeling of the solubility of ergosterol in supercritical carbon dioxide." Journal of the Taiwan Institute of Chemical Engineers. 44 (1). pp. 19-26. 2013. DOI: 10.1016/j.jtice.2012.09.001

[2] Nasri, L., Bensaad, S., Bensetiti, Z. "Modeling the Solubility of Dihydroxybenzoic Acid and Methylbenzoic Acid Isomers in Supercritical Carbon Dioxide." International Journal of Thermodynamics. 17 (2). pp. 81-85. 2014. DOI: $10.5541 /$ ijot.513

[3] Baseri, H., Lotfollahi, M. N. "Effects of expansion parameters on characteristics of gemfibrozil powder produced by rapid expansion of supercritical solution process." Powder Technology. 253. pp. 744-750. 2014. DOI: 10.1016/j.powtec.2013.12.046

[4] Huang, C. Y., Lee, L. S., Su, C. S. "Correlation of solid solubilities of pharmaceutical compounds in supercritical carbon dioxide with solution model approach." Journal of the Taiwan Institute of Chemical Engineers. 44 (3). pp. 349-358. 2013. DOI: 10.1016/j.jtice.2012.12.004

[5] Housaindokht, M. R., Haghighi, B., Bozorgmehr, M. R. "A comparison among three equations of state in predicting of some solids in supercritical carbon dioxide." Korean Journal of Chemical Engineering. 24 (1). pp. 102-105. 2007. DOI: 10.1007/s11814-007-5017-0

[6] Yazdizadeh, M., Eslamimanesh, A., Esmaeilzadeh, F. "Thermodynamic modeling of solubilities of various solid compounds in supercritical carbon dioxide: Effects of equations of state and mixing rules." Journal of Supercritical Fluids. 55. pp. 861-875. 2011. DOI: $10.1016 /$ j.supflu.2010.10.019

[7] Wang, L.-H., Lin, S.-T. "A predictive method for the solubility of drug in supercritical carbon dioxide." Journal of Supercritical Fluids. 85. pp. 81-88. 2014. DOI: 10.1016/j.supflu.2013.10.019
[8] Su, C. S. "Prediction of solubilities of solid solutes in carbon dioxideexpanded organic solvents using the predictive Soave-Redlich-Kwong (PSRK) equation of state." Chemical Engineering Research and Design. 91 (6). pp. 1163-1169. 2013. DOI: 10.1016/j.cherd.2012.12.004

[9] Asgarpour, K. M., Hallaji, S. A., Shahbeig, H., Arif, A., Dalirsefat, H., Salehi, M. A. "A Novel Equation of State: Determination and Validation for Dyes and Drugs Solubility Calculations in Supercritical Carbon Dioxide." Periodica Polytechnica Chemical Engineering. 58 (2). pp. 179-194. 2014. DOI: 10.3311/PPch.7436

[10] Baseri, H., Haghighi-Asl, A., Lotfollahi, M. N. "Thermodynamic modeling of solid solubility in supercritical carbon dioxide: comparison between mixing rules." Chemical Industry \& Chemical Engineering Quarterly. 19 (3).pp. 389-398. 2013. DOI: 10.2298/CICEQ120203074B

[11] Ardjmand, M., Mirzajanzadeh, M., Zabihi, F. "Measurement and Correlation of Solid Drugs Solubility in Supercritical Systems." Chinese Journal of Chemical Engineering. 22 (5). pp. 549-558. 2014. DOI: 10.1016/S1004-9541(14)60073-2

[12] Shojaee, S. A., Rajaei, H., Zeinolabedini, H., Lashkarbolooki, M., Esmaeilzadeh, F. "Experimental measurement and correlation for solubility of piroxicam (a non-steroidal anti-inflammatory drugs (NSAIDs)) in supercritical carbon dioxide." Journal of Supercritical Fluids. 80. pp. 38-43. 2013. DOI: 10.1016/j.supflu.2013.03.015

[13] Chrastil, J. "Solubility of solids and liquids in supercritical gases." Journal of Physical Chemistry. 86. pp. 3016-3022. 1982. DOI: 10.1021/j100212a041

[14] Méndez-Santiago, J., Teja, A. S. "Solubility of solids in supercritical fluids: consistency of data and a new model for cosolvent systems." Industrial \& Engineering Chemistry Research. 39. pp. 4767-4771. 2000. DOI: $10.1021 / \mathrm{ie} 000339 \mathrm{u}$

[15] Jafari, N. S. H., Abolghasemi, S. H., Moosavian, H., Maragheh, M. A. "Prediction of solute solubility in supercritical carbon dioxide: a novel semi-empirical model." Chemical Engineering Research and Design. 8. pp. 893-898. 2010. DOI: 10.1016/j.cherd.2009.12.006

[16] Aghamiri, S. F., Nickmand, Z. "Prediction of Solubility of Cholesterol in Supercritical Solvents." Separation Science and Technology. 45 (14). pp. 2119-2129. 2010. DOI: 10.1080/01496395.2010.504448

[17] Redlich, O., Kwong, J. N. S. "On the Thermodynamics of Solutions. V. An Equation of State. Fugacities of Gaseous Solutions." Chemical Reviews. 44 (1). pp. 233-244. 1949. DOI: 10.1021/cr60137a013

[18] Heidaryan, E., Jarrahian, A. "Modified Redlich-Kwong equation of state for supercritical carbon dioxide." Journal of Supercritical Fluids. 81. pp. 92-98. 2013. DOI: 10.1016/j.supflu.2013.05.009

[19] Peng, D. Y., Robinson, D. B. "A new two-constant equation of state." Industrial \& Engineering Chemistry Fundamentals. 15 (1). pp. 59-64. 1976. DOI: 10.1021/1160057a011

[20] Chen, Y. P., Chen, Y. M., Tang, M. "Solubilities of Cinnamic Acid, Phenoxyacetic Acid and 4-Methoxyphenylacetic Acid in Supercritical Carbon Dioxide." Fluid Phase Equilibria. 275 (1). pp. 33-38. 2009. DOI: 10.1016/j.fluid.2008.09.009

[21] Cortesi, A., Kikic, I., Alessi, P., Turtoi, G., Garnier, S. "Effect of chemical structure on the solubility of antioxidants in supercritical carbon dioxide: experimental data and correlation." Journal of Supercritical Fluids. 14. pp. 139-144. 1999. DOI: 10.1016/S0896-8446(98)00119-3

[22] Huang, Z., Lu, W. D., Kawi, S., Chiew, Y. C. "Solubility of aspirin in supercritical carbon dioxide with and without acetone." Journal of Chemical \& Engineering Data. 49 (5). pp. 1323-1327. 2004. DOI: $10.1021 /$ je0499465 
[23] Barna, L., Blanchard, J. M., Rauzy, E., Berro, C. "Solubility of fluoranthene, chrysene, and triphenylene in supercritical carbon dioxide." Journal of Chemical \& Engineering Data. 41 (6). pp. 14661469. 1996. DOI: $10.1021 / \mathrm{je} 960189 \mathrm{n}$

[24] Park, C. I., Shin, M. S., Kim, H. "Solubility of climbazole and triclocarban in supercritical carbon dioxide: Measurement and correlation." Journal of Chemical Thermodynamics. 41 (1). pp. 30-34. 2009. DOI: 10.1016/j.jct.2008.08.009

[25] Yamini, Y., Bahramifar, N. "Solubility of Polycyclic Aromatic Hydrocarbons in Supercritical Carbon Dioxide." Journal of Chemical \& Engineering Data. 45 (1). pp. 53-56. 2000. DOI: 10.1021/je990129s

[26] Yun, S. L. J., Liong, K. K., Gurdial, G. S., Foster, N. R. "Solubility of Cholesterol in Supercritical Carbon Dioxide." Industrial \& Engineering Chemistry Research. 30. pp. 2476-2482. 1991.

DOI: $10.1021 / \mathrm{ie} 00059 \mathrm{a} 018$
[27] Huang, Z., Kawi, S., Chiew, Y. C. "Solubility of cholesterol and its esters in supercritical carbondioxide with and without cosolvents." Journal of Supercritical Fluids. 30 (11). pp. 25-39. 2004. DOI: 10.1016/S0896-8446(03)00116-5

[28] Coelho, J. P., Naydenov, G. P., Yankov, D. S., Stateva, R. P. "Experimental Measurements and Correlation of the Solubility of Three Primary Amides in Supercritical CO2: Acetanilide, Propanamide, and Butanamide." Journal of Chemical \& Engineering Data. 58 (7). pp. 2110-2115. 2013. DOI: 10.1021/je400357t

[29] Pitzer, K. S. "The Volumetric and Thermodynamic Properties of Fluids. I. Theoretical Basis and Virial Coefficients." Journal of the American Chemical Society. 77 (13). pp. 3427-3433. 1955.

DOI: $10.1021 / \mathrm{ja} 01618 \mathrm{a} 001$ 